\title{
Laparoscopic Sleeve Gasterectomy Reduces Inflammation and Cardiometabolic Risk in Obese Patients
}

\author{
FG Nazirov, ZR Khaybullina*, SH KH Khashimov and UM Makhmudov \\ Republican Specialized Center of Surgery named after academician V. Vakhidov, Ministry of Health Republic of Uzbekistan, Tashkent, Uzbekistan
}

\begin{abstract}
Obesity is associated with Metabolic Syndrome (MetS) and high cardiovascular risk as well as inflammation. Bariatric surgery is the most effective treatment of obesity and cardiovascular risk reduction. The aim of this research was to evaluate the Laparoscopic Sleeve Gasterectomy (LSG) effect on cardiometabolic risk factors, proinflammatory cytokines and oxidative stress markers in 25 women with morbid obesity (body mass index=45.4 $\pm 2.0 \mathrm{~kg} / \mathrm{m}^{2}$ ). LSG is mini-invasive operation without radical reconstruction of gastrointestinal tract. It was established that after LSG there were no activation of inflammation, in contrast, there was reduction of proinflammatory cytokines (interleykin-6, tumor necrosis factor-alpha) and C-reactive protein in the blood at early ( $7^{\text {th }}$ day) and late ( 3 month) period after operation. LSG led to a decrease in body weight and reduces cardiometabolic risk by normalizations of lipidomic profile (high-density lipoprotein cholesterol, triglyceride concentration in blood), optimizing the visceral fat tissue metabolism and reduction of inflammation and oxidative stress.
\end{abstract}

Keywords: Laparoscopic Sleeve Gasterectomy (LSG); Inflammation; Cardiometabolic risk; Obesity

\section{Introduction}

Obesity is a major public health problem; it is associated with Metabolic Syndrome (MetS) and high cardiovascular risk as well as factor of the risk to premature death [1]. Many of baseline risk factors for Coronary Heart Disease (CHD) such as serum level of Total Cholesterol (TC), High-Density Lipoprotein Cholesterol (HDL-C), Triglyceride (TG), age, systolic and diastolic blood pressure, Body Mass Index (BMI), Waist Circumference (WC), and diabetes are linked with obesity [2]. The TG/HDL-C index is an independent predictor for $\mathrm{CHD}$ and can identify cardiometabolic risk [3]. Deposition of TG in adipose tissue is associated with macrophages accumulation and proinflammatory cytokines (interleykin-6 (IL-6), tumor necrosis factor alpha (TNF-alpha)) production, which leads to a stimulation of inflammation, adipose tissue macrophages are elevated in obesity and perpetuate inflammatory pathways [4]. It has been shown 111 genes, associated with inflammation, that were differentially expressed in subcutaneous and visceral adipose tissue [5]. The expression of critical pro-inflammatory genes (IL-6, IL-8 etc.) in adipose tissue of the individuals with morbid obesity is substantially higher [6]. Proinflammatory cytokines, NADPH oxidase activation and Reactive Oxygen Species (ROS) overproduction, local hypoxia of adipocytes, viruses and microorganisms such as Cytomegalovirus (CMV), Helicobacter Pillory (HP), Chlamydophyla Pneumonia (CP) might induce an inflammation in adipose tissue $[7,8]$. Data of metaanalysis that suggested CMV infection is associated with an increased risk for CHD, especially among Asian populations [9]. Triggering of inflammation in adipose tissue occurs through innate immunity receptors-Toll-Like Receptors (TLR); they can be activated by bacterial lipopolysaccharide, free fatty acids, products of lipids degradation [10]. Elevated circulating lipopolysaccharide binding protein (LBP) was associated with obesity, metabolic syndrome, and type 2 diabetes in apparently healthy Chinese, that suggested a role of lipopolysaccharide via initiation of innate immune mechanisms in metabolic disorders [11]. Activation of TLR triggers different intracellular signaling pathways involving $\mathrm{NFkB}$ and transcriptional factors for various proinflammatory cytokines, chemokines and regulatory molecules [12]. Inflammation in obesity causes proatherogenic effect. Because obesity, MetS and atherosclerosis are considered chronic inflammatory states, proinflammatory factors such as C-reactive protein (CRP), IL-6 might be involved in the pathogenesis of obesity and MetS as well as oxidative stress and endothelial dysfunction and should be reduced in obese patients. Bariatric surgery is the most effective treatment of obesity and cardiovascular risk reduction, but it is associated with inflammation in post operative period, which can contribute to deterioration of treatment results in obese patients [13]. There are 3 types of bariatric surgical procedures: Restrictive, malabsorptive, and combined operations. Gastric bypass surgery is a combination of restriction and malabsorption and has been shown to achieve a significantly higher degree of weight loss than restrictive bariatric surgery [14]. Not only weight loss and lipidomic profile normalization, but inflammation reduction can provide decreasing of cardiometabolic risk. Whether metabolic risk factors modify this association is unclear. We aimed to study Laparoscopic Sleeve Gasterectomy (LSG) effect on cardiometabolic risk factors, proinflammatory cytokines and oxidative stress markers at obese patients.

\section{Material and Methods}

Between January 2015 and September 201625 women with morbid obesity were identified in AS "Republican Specialized Center of Surgery named after academician V. Vakhidov". Limitations of current study: Including criteria were-sex (only women), age (only 18-44 years), morbid obesity (BMI $\left.>40.0 \mathrm{~kg} / \mathrm{m}^{2}\right)$, nonsmoking. All of 25 women with morbid obesity were treated by LSG. Duration of observation was 6 months after LSG. For each patient up to 10 controls were matched by

*Corresponding author: Khaybullina ZR, Republican Specialized Center of Surgery named after academician V. Vakhidov, Ministry of Health Republic of Uzbekistan, Tashkent, Uzbekistan, Tel: +998 71 239-47-95; E-mail: zrkhaybullina1@gmail.com

Received November 01, 2016; Accepted November 17, 2016; Published November 23, 2016

Citation: Nazirov FG, Khaybullina ZR, Khashimov SK, Makhmudov UM (2016) Laparoscopic Sleeve Gasterectomy Reduces Inflammation and Cardiometabolic Risk in Obese Patients. Cardiovasc Pharm Open Access 5: 200. doi: 10.4172/2329-6607.1000200

Copyright: $\odot 2016$ Khaybullina ZR, et al. This is an open-access article distributed under the terms of the Creative Commons Attribution License, which permits unrestricted use, distribution, and reproduction in any medium, provided the original author and source are credited. 
pre-surgery BMI, WC, age, laboratory tests. Laboratory tests included CRP and routine biochemical tests (lipidomic panel, total protein, albumin, glucose, uric acid (UA)), which were made in automatic biochemical analyzer "VITROS-350" (Ortho Clinical Diagnostics, USA). IL-6, TNF-a, marker of endothelial proliferation and migrationvascular endothelial growth factor (VEGF), antibodies to CMV, CP, HP were measured in the blood serum using commercially available ELISA kits (VECTOR-BEST, Russia) in immunoassay analyzer ST-360, (China). General blood count was made by automatic hematological analyzer BC 5800 (Mindray, China). Malondialdehyde (MDA) was analyzed according to procedure of Ohkawa on reaction with thiobarbituric acid in Al-Gayyar's modifications [15]. Catalase activity was determined by the speed of hydrogen peroxide degradation in the semi-automatic analyzer "Screen Master Plus" (Hospitex Diagnostics, Italy). LSG was performed on laparoscopic track (Karl Storz, GMBH \& CoKG and Germany) with energy platform Force Triad and technology Liga Sure (USA) and endoscopic staplers (Ethicon Endo Surgery,USA). The results are presented as the $\mathrm{M} \pm \mathrm{m}$, independent Student $\mathrm{t}$-test was applied to find out the statistical significant difference $(\mathrm{p}<0.05)$ between the groups.

\section{Results and Discussion}

In morbid obesity group an average age was $34,25 \pm 1.7$; $\mathrm{WC}=110$, $1 \pm 1.7 ; \mathrm{BMI}=45,4 \pm 2.0 \mathrm{~kg} / \mathrm{m}^{2} .10$ controls were women-volunteer at age $38,4 \pm 1.9$ without obesity, $\mathrm{BMI}=23,4 \pm 0.3 \mathrm{~kg} / \mathrm{m}^{2}, \mathrm{WC}=76,1 \pm$ $1.0 \mathrm{sm}$. Level of TC, TG, HDL-C levels were increased in obese women versus to the control in $1.2(\mathrm{p}>0.05) ; 2.7(\mathrm{p}<0.05)$ and $1.5(\mathrm{p}<0.05)$ times respectively; TG/HDL-C ratio was increased in 3,9 times $(\mathrm{p}<0.05)$; $100 \%$ of obese women have 3 from 5 criteria's of MetS-TG level more $1.69 \mathrm{mmol} / \mathrm{l}$; HDL-C level below $1.3 \mathrm{mmol} / \mathrm{l}$, WC more $80 \mathrm{sm}$, that indicates high cardiometabolic risk. Proinflammatory cytokines levels: IL-6, TNF-alpha and CRP were increased exactly versus to the control $(\mathrm{p}<0.05)$ in 2,7; 5,3 and 3,5 times respectively as well as UA, which was above the control in 2,5 times $(\mathrm{p}<0.05)$. The $\mathrm{WBC}$ were within referents interval $\left(4-9 \times 10^{9} / 1\right)$, however was exactly above the control $(\mathrm{p}<0.05)$; the contents of monocytes were increased in 2,0 times versus the control; MDA concentration was increased in 1,3 times $(r<0.05)$, but catalase activity and VEGF concentration did not differs from the control (Table 1). Monocytes are precursors of tissue macrophages, increasing of monocytes amount indirectly shows inflammatory reaction. AntiCMV IgG was increased above the cut off both at control and Morbid Obesity (MO) groups. This data indicates high seropositivity for CMV in observed population. $96 \%$ of women with MO were seronegative to $\mathrm{CP}, 76 \%$ were seronegative to $\mathrm{HP}$ and there were no difference between control and MO groups. This data suggests, that CMV, CP and HP are equally comes to light both in normal weight and morbid obesity women. The role of infection factor in morbid obesity is speculative. General seropositivity to CMV revealed in our search does contradict with results of population study in California (2010), when more than $95 \%$ of population were seropositive to human CMV and KaplanMeier survival curves suggested worse cardiovascular disease survival for individuals in the highest quartile of human CMV IgG antibody titers over 9 years of follow up [16].

Early postoperative period after LSG ( $7^{\text {th }}$ day) characterized by significant decreasing TG, TC and TG/HDL-C ratio $(\mathrm{p}<0.05)$ versus pre-surgery level. This changes took place long before weight loss and may be caused by positive changes in Adipose Tissue (AT) metabolism after LSG due to decreasing of inflammation and TG accumulation in AT. This hypothesis is confirmed by IL- 6 and CRP concentrations decreasing exactly on the $7^{\text {th }}$ day after LSG.

LSG provides effective weight loss, reduction WC and visceral adipose tissue 3 months after the surgery. BMI and WC were reduced on

\begin{tabular}{|c|c|c|c|c|}
\hline Group of patients & $\begin{array}{c}\text { Control } \\
\text { group } n=10\end{array}$ & $\begin{array}{c}\text { Before LSG } \\
n=25\end{array}$ & $\begin{array}{l}\text { After } \operatorname{LSG} 7^{\text {th }} \\
\text { day } n=25\end{array}$ & $\begin{array}{l}\text { After LSG } 3 \\
\text { month } n=12\end{array}$ \\
\hline WC, sm & $76.1 \pm 1.0$ & $110.1 \pm 1.7^{*}$ & $109.2 \pm 1.4^{*}$ & $88 \pm 2.1^{*}$ \\
\hline $\mathrm{BMI}, \mathrm{kg} / \mathrm{m}^{2}$ & $23.4 \pm 0.3$ & $45.4 \pm 2.0^{*}$ & $42.1 \pm 1.7^{\star}$ & $35.2 \pm 1.4^{*}$ \\
\hline $\mathrm{TC}, \mathrm{mmol} / \mathrm{l}$ & $4.4 \pm 0.1$ & $5.1 \pm 0.3^{*}$ & $4.1 \pm 0.3^{* *}$ & $3.1 \pm 0.1^{* * *}$ \\
\hline $\mathrm{TG}, \mathrm{mmol} / \mathrm{l}$ & $0.93 \pm 0.19$ & $2.55 \pm 0.19^{*}$ & $1.8 \pm 0.21^{* * *}$ & $1.3 \pm 0.11^{* *}$ \\
\hline $\mathrm{HDL}-\mathrm{C}, \mathrm{mmol} / \mathrm{l}$ & $1.34 \pm 0.03$ & $0.91 \pm 0.12^{*}$ & $0.90 \pm 0.04^{*}$ & $1.11 \pm 0.06^{*}$ \\
\hline TG/HDL-C ratio & $0.7 \pm 0.1$ & $2.8 \pm 0.1^{*}$ & $2.0 \pm 0.2^{*} \cdot * *$ & $1.2 \pm 0.1^{* * *}$ \\
\hline Glucose, $\mathrm{mmol} / \mathrm{l}$ & $4.7 \pm 0.1$ & $5.8 \pm 0.2^{*}$ & $6.1 \pm 0.1^{*}$ & $5.0 \pm 0.2^{* *}$ \\
\hline IL-6, pg/ml & $8.7 \pm 1.1$ & $23.5 \pm 3.9^{*}$ & $16.6 \pm 3.2^{* * *}$ & $15.0 \pm 1.4^{*}{ }^{* *}$ \\
\hline TNF, pg/ml & $4.3 \pm 1.2$ & $23.1 \pm 4.2^{*}$ & $27.9 \pm 2.7^{\star}$ & $10.8 \pm 1.0^{*}$ \\
\hline CRP mg/l & $4.4 \pm 0.8$ & $15.5 \pm 0.2^{*}$ & $11.0 \pm 0.4^{* *}$ & $5.0 \pm 0.5^{* *}$ \\
\hline $\mathrm{UA}, \mathrm{mkmol} / \mathrm{l}$ & $156 \pm 6$ & $389 \pm 20^{*}$ & $359 \pm 31^{*}$ & $268 \pm 13^{* * *}$ \\
\hline $\begin{array}{l}\mathrm{MDA}, \mathrm{nmol} / \mathrm{mg} \\
\text { protein } \times \mathrm{min}\end{array}$ & $4.7 \pm 0.3$ & $6.3 \pm 0.2^{*}$ & $5.9 \pm 0.3^{*}$ & $5.1 \pm 0.2^{* *}$ \\
\hline Catalase, E/l & $19.2 \pm 1.8$ & $23.3 \pm 1.1$ & $24.1 \pm 0.8$ & $22.1 \pm 0.5$ \\
\hline VEGF, pg/ml & $112 \pm 15$ & $156.2 \pm 68$ & $164 \pm 22$ & $168 \pm 16$ \\
\hline WBC, $10^{9} / \mathrm{I}$ & $4.9 \pm 0.4$ & $7.03 \pm 0.56^{*}$ & $7.60 \pm 0.15$ & $5.60 \pm 0.44^{* *}$ \\
\hline Monocytes, \% & $3.5 \pm 0.3$ & $7.0 \pm 0.2^{*}$ & $9.0 \pm 0.7^{* *}$ & $7.8 \pm 1.0^{*}$ \\
\hline Lymphocytes, \% & $35.6 \pm 5.0$ & $34.6 \pm 2.2$ & $32.1 \pm 1.9$ & $35.3 \pm 1.9$ \\
\hline Total protein, g/l & $68.4 \pm 2.1$ & $71.0 \pm 2.2$ & $72.1 \pm 1.5$ & $74.0 \pm 1.8$ \\
\hline Albumin, $g / l$ & $46.2 \pm 1.1$ & $44.6 \pm 1.3$ & $45.2 \pm 1.8$ & $48.0 \pm 1.1$ \\
\hline $\begin{array}{l}\text { Anti CMV IgG, E/ml } \\
\text { (cut off }=0.41 \pm 0.05 \text { ) }\end{array}$ & $8.1 \pm 2.1$ & $7.23 \pm 0.5$ & $4.01 \pm 0.11^{*}$ & $3.75 \pm 0.22^{*}$ \\
\hline
\end{tabular}

"p<0.05: Versus control; " $p<0.05$ : Versus baseline level before LSG

Table 1: Cardiometabolic risk factors before and after LSG.

$25 \%$ and $15 \%$ respectively versus pre-surgery level 3 months after LSG. IL-6 and TNF-alpha decreased in 1,6 and 2,2 time versus level before surgery, TG, CRP and MDA was not differ from the control ( $p>0.05$ ); HDL-C, TC, TG/HDL-C ratio and UA were exactly $(\mathrm{p}<0.05)$ differ versus data before LSG. We believe that reduction of adipose tissue mass and inflammation in it, as well as normalization of its metabolism, caused these positive changes in lipidomic profile. It is considered that decreasing of TNF-alpha is favorable for insulin resistance reduction and carbohydrates and lipids metabolism optimization [17]. Oxidative stress after LSG reduced too: Concentration of MDA and catalase activity were corresponded to control, UA decreased on $68 \%$ after LSG, that indicates reduction of antioxidant system mobilization, because UA has $50 \%$ of total antioxidant capacity of blood at levels as high as $285 \mu \mathrm{mol} / \mathrm{L}$; it does act against peroxynitrite, peroxides, and hypochlorous acid [18].

Level of anti-CMV IgG decreased in 1,9 times versus pre-surgery level 3 months after LSG. Decreasing of anti-CMV IgG after LSG is beneficial, because anti-CMV IgG have homology to heart shock proteins, which leads to a stimulation of TLR-4, thereby initiating inflammation and disrupting normal adipocytokine profile, as well as endothelial dysfunction and atherogenesis.

LSG is restrictive bariatric procedure, which provides strong decreasing of volume of the belle (gaster) to 60-150 ml. Surgical technique of LSG includes removing the major curvature of belle, saving of cardiac gastric sphincter and forming the narrow gastric tube along small curvature of belle, whose volume is $60-150 \mathrm{ml}$. Strong decreasing of the belly's volume causes reduction of meal's portion, thereby patient can eat only small amount of meal (30-60 ml) 5-6 times a day. LSG does not cause malabsorbtion and digestive tract reconstruction, but it causes elevation of incretines secretion. Incretines provides insulinocytes activation and early secretion of the insulin as a response to hit of the food in gastrointestinal tract. Some of incretines, such as glucagon-like peptide-1 (GPP-1) can inhibited gluconeogenesis and glycogen degradation in liver, raises the consumption and salvaging 
the glucose in skeletal musculature. Hypothalamus and pituitary gland have receptor to GPP-1 too, stimulation of these receptors decreased appetite [19].

Our data showed that total protein, albumin concentrations and total lymphocytes amount were corresponded to the control group both $7^{\text {th }}$ day and 3 month after LSG that proves absence of malabsorbtion and immunodeficiency state after LSG. In spite of using small portion of the meal after LSG, patients did not feel discomfort, they felt themselves subjective better.

The advantages of LSG are that it is mini-invasive, without radical reconstruction of digestive tract. LSG was not accompanied with inflammation both at early and last period after surgery, in contrast, proinflammatory markers levels decreased after LSG. In particular, it has been shown in our previous experience that after bilio-pancreatic diversion concentrations of CRP, IL-6 ware increased [20]. After LSG there were no activation of inflammation, in contrast, there was reduction of proinflammatory cytokines and CRP.

\section{Conclusion}

LSG was not accompanied by activation of the system inflammation both at early periods and at 3 months after surgery. LSG promotes liquidation of the inflammation and metabolic disorders in patients with morbid obesity. LSG causes body mass index and waist circumference decreasing on $25 \%$ and $14 \%$ after 3 month post-surgery versus data before treatment, that approve visceral fat reduction. LSG reduces cardiometabolic risk by normalizations of lipidomic profile and optimizing the visceral fat tissue metabolism by reduction of inflammation and oxidative stress.

\section{Acknowledgement}

This work was done with support of grant FDSS-12-3 "Role of a chronic subclinical inflammation in pathogenesis of metabolic syndrome, an establishment diagnostic and prognostic value of its markers at an atherosclerosis"

\section{References}

1. Marczak L, O'Rourke K, Shepard D (2016) When and why people die in the United States. JAMA 315: 241.

2. Hadaegh F, Khalili D, Ghasemi A, Tohidi M, Sheikholeslami F, et al. (2008) Triglyceride/HDL-cholesterol ratio is an independent predictor for coronary heart disease in a population of Iranian men. Nutr Metab Cardiovasc Dis 19: 401-408.

3. Salazar MR, Carbajal HA, Espeche WG, Aizpurúa M, Maciel PM, et al. (2014) Identification of cardiometabolic risk: visceral adiposity index versus triglyceride/HDL cholesterol ratio. Am J Med 127: 152-157.

4. Bouwman JJM, Diepersloot RJA, Visseren FLJ (2009) Intracellular Infections Enhance Interleukin-6 and Plasminogen Activator Inhibitor 1 Production by Cocultivated Human Adipocytes and THP-1 Monocytes. Clin Vaccine Immunol pp: 1222-1227

5. Du Plessis J, Van Pelt J, Korf H, Mathieu C, van der Schueren B, et al. (2015) Association of Adipose Tissue Inflammation with Histological Severity of Nonalcoholic Fatty Liver Disease. Gastroenterology 5085: 771-774.

6. Spoto B, Di Betta E, Mattace Raso F, Sijbrands E, Vilardi A, et al . (2014) Proand anti-inflammatory cytokine gene expression in subcutaneous and visceral fat in severe obesity. Nutr Metab Cardiovasc Dis 24: 1137-1143.
7. Fernández BD, Consuegra SL, Peñafiel J, Cabrera de León A, Vila $\mathrm{J}$, et al. (2014) Metabolic and inflammatory profiles of biomarkers in obesity, metabolic syndrome, and diabetes in a Mediterranean population DARIOS Inflammatory study. Rev Esp Cardiol 67: 624-631.

8. Shvarts V (2011) Inflammation of the adipose tissue (Part 4). Obesity: a new infectious disease. (A literature review). Problems of Endocrinology (in Russian) 57: 63-71.

9. Ji YN, An L, Zhan P, Chen XH (2012) Cytomegalovirus infection and coronary heart disease risk: a meta-analysis. Mol Biol Rep 39: 6537-6546.

10. Shvarts V (2009) Adipose tissue as endocrine organ. Problems of Endocrinology (in Russian) 55: 38-44.

11. Sun L, Yu Z, Ye X, Zou S, Li H, et al. (2010) A marker of endotoxemia is associated with obesity and related metabolic disorders in apparently healthy Chinese. Diabetes Care 33:1925-1932.

12. Janket SJ, Ackerson LK (2015) What is passing through toll gate 4: Lipids or infection. Arch Oral Biol 9969: 18-27.

13. Schumann R, Shikora SA, Sigl JC, Kelley SD (2014) Association of metabolic syndrome and surgical factors with pulmonary adverse events, and longitudinal mortality in bariatric surgery. Br J Anaesth 114: 83-90.

14. Reza A, Greenstein AS, Yadav R, Jeziorska M, Hama S (2013) Effects of Bariatric Surgery on Human Small Artery Function. J Am Coll Cardiol 62: 128135

15. Al Gayyar MM, Eissa LA, Rabie AM, El Gayar AM (2007) Measurements of oxidative stress status and antioxidant activity in chronic leukaemia patients. J Pharm Pharmacol 59: 409-417.

16. Crumpacker CS (2010) Invited commentary: human cytomegalovirus, inflammation, cardiovascular disease, and mortality. Am J Epidemiol 172: 372374

17. Wieser V, Moschen AR, Tilg $H$ (2013) Inflammation, cytokines and insulin resistance: a clinical perspective. Arch Immunol Ther Exp (Warsz) 61: 119-125.

18. Sautin Y, Richard J (2008) Uric Acid: The Oxidant-Antioxidant Paradox Nucleosides, Nucleotides and Nucleic Acids 27: 608-619.

19. Dedov II, lashkov YI, Ershova EV (2012) Incretins and its influence on diabetes mellitus 2 type in patients with morbid obesity after bariatric surgery. Obesity and Metabolism (in Russian) 2: 3-10.

20. Kosnikova IV, Bajenov LG, Nizamkhodjaev ZM, Ligay RE (2012) Metabolic effects of surgical treatment of morbid obesity. Bulleten of doctors of Uzbekistan 2: 84-86. 